Physical Therapy

academic.oup.com/ptj

Postprint

Cite this article: Boisgontier MP, Iversen MD (2020) Physical inactivity: a behavioral disorder in the physical therapist's scope of practice. Physical Therapy.

https://doi.org/10.1093/ptj/pzaa011

Received: August 6, 2019

Accepted: November 20, 2019

*Author for correspondence:

Matthieu P. Boisgontier

E-mail : matthieu.boisgontier@uottawa.ca

Twitter: @MattBoisgontier

\section{Physical inactivity: a behavioral disorder in the physical therapist's scope of practice}

\author{
Matthieu P. Boisgontier $1,{ }^{*}$, Maura D. Iversen2 \\ 1 School of Rehabilitation Sciences, Faculty of Health Sciences, University of Ottawa, Ottawa, \\ ON, Canada \\ 2 College of Health Professions, Sacred Heart University, Fairfield, Connecticut; Department of \\ Medicine, Section of Clinical Sciences, Brigham and Women's Hospital, Harvard Medical \\ School, Boston, Massachusetts; and Department of Women's and Children's Health, \\ Karolinska Institute, Stockholm, Sweden
}

\section{Introduction}

In health, the gold standard is a state of complete physical, mental, and social well-being.1 This state is weakened by physical inactivity, which involves a higher risk of cardiovascular disease, 2 hypertension, 3 diabetes, 2,4 cancer, 5 depression, 6 and obesity. 7 Moreover, $6 \%$ to $10 \%$ of all deaths from non-communicable diseases worldwide can be attributed to physical inactivity.8 These adverse effects of physical activity provide evidence that physically active individuals are closer to the gold standard of health than inactive individuals. Therefore, physical activity - not inactivity - should be the standard reference behavior. In this framework, physical inactivity is a clinically significant disturbance in an individual's behavior, which is the definition of a behavioral disorder.9 Therefore, physical inactivity should be treated as such.

\section{Epidemiology}

A recent study involving 1.9 million participants who represented $96 \%$ of the world's population showed that more than a quarter of all adults are physically inactive, which represents more than 1.4 billion adults.10 The prevalence of physical inactivity is highest in Latin America, the Caribbean, high-income Western countries, and high-income Asia Pacific. These data also confirmed previous findingsi1 demonstrating higher levels of physical inactivity in women than in men, with some of the biggest differences in south and central Asia, the Middle East, and north Africa. While multiple articles mention a pandemic of physical inactivity,11,12 the global prevalence of physical inactivity was stable between 2001 and 2016 with an average change across the 65 countries of less than $0.01 \% .10$ Yet, wide variations in physical inactivity were observed across countries. Levels of physical inactivity were increasing in 37 countries, whereas they were decreasing in 28 countries. The largest increases ( $>15 \%)$ occurred in high-income countries such as Germany and Singapore, while the largest decreases $(>15 \%)$ occurred in east and southeast Asia.

\section{Physical Inactivity Disorder}

During the past two decades, society has encouraged people to be more physically active. 8,13 As a result, most individuals are now cognizant of the positive effects of regular physical activity and have the intention to be active.14 Yet, this intention is not sufficient alone, as engagement in physical activity is often not executed.15 The World Health Organization (WHO) defines impulse control disorders, a specific type of behavioral disorder, as "the repeated failure to resist an impulse, drive, or urge to perform an act that is rewarding to the person, at least in the short-term, despite consequences such as longer-term harm to the individual." 9 Recent studies have shown that individuals with stronger impulses toward physical inactivity fail to implement their intention to be physically active because of a weaker ability to control these impulses.16,17 Therefore, physical
Not the version of record. For the version of record, visit https://doi.org/10.1093/ptj/pzaa011 
inactivity can be characterized as the repeated failure to resist an impulse, drive, or urge to minimize energy expenditure, 18 which matches the WHO definition of an impulse control disorder. Two meta-analyses examining the effectiveness of exercise-related interventions based on motivation theories showed small effect sizes and

high levels of unexplained variance regarding intervention outcomes.19,20 Therefore, the development of new interventions targeting the automatic evaluation of exercise-related stimuli to influence decision-making and behavior regarding physical activity may be a better approach. Indeed, the effect of such interventions has already shown its potential in other behavioral disorders such as alcohol use disorders.21

\section{Diagnosis}

From a health perspective, physical inactivity, also named insufficient physical activity, 10 is defined as the failure to meet the recommendations on physical activity for health. The latest recommendations from the $\mathrm{WHO}_{22}$ and the US Department of Health and Human Services23 address multiple population groups. Preschool-aged children aged 3 to 5 years should be physically active throughout the day. Children and adolescents aged 6 to 17 should perform $60 \mathrm{~min}$ or more of moderate-tovigorous physical activity daily. Throughout the week, adults aged 18 to 64 and older adults age 65 years and above should perform at least $150 \mathrm{~min}$ of moderateintensity, or $75 \mathrm{~min}$ of vigorous-intensity aerobic physical activity, or an equivalent combination of moderate- and vigorous-intensity aerobic activity. They should also perform muscle-strengthening activities on 2 or more days a week. Pregnant and postpartum women should engage in at least 150 min of moderate-intensity aerobic activity a week. Adults with chronic conditions or disabilities, who are able, should follow the key guidelines for adults and perform both aerobic and muscle-strengthening activities. The inability to reach these recommendations, i.e., physical inactivity, can be diagnosed indirectly using self-report questionnaires and diaries, which could be used as screening tools, and directly using commercially available devices such as accelerometers, pedometers, and armbands.24 Yet, a gold standard assessment of the physical inactivity disorder is still missing, which may partly explain the current absence of reimbursement for treating physical inactivity in the United States.

\section{Etiology}

Physical inactivity has shown to be related to multiple factors including genetics,25 older age,26 lower education,26,27 lower cognitive resources,27,28 poor neighborhood conditions, $26-28$ ethnicity, 26 disadvantaged socioeconomic circumstances, 29 and weak impulse control.16-18

\section{Pathophysiology}

Physical inactivity disorder is associated with a loss of lean body mass, which is the result of a chronic imbalance between muscle protein synthesis and breakdown. 30 This imbalance can be exacerbated during the progression of aging (Figure) and lead to sarcopenia, 31 which is characterized by progressive and generalized loss of skeletal muscle mass and strength. Sarcopenia is a major contributor to the risk of physical frailty, functional impairment, poor health-related quality of life, and premature death.32 Physical inactivity disorder is associated with a reduced bone density, 33 which increases bone fragility and constitutes a risk factor for osteoporosis.34 Physical inactivity disorder is associated with higher fat mass 35 and being overweight or obese.7 Physical inactivity disorder is also a risk factor for cardiovascular disease2, hypertension,3 diabetes,2,4 cancer,5 and depression.6

\section{Prognosis}

Based on data from the National Institutes of HealthAmerican Association of Retired Persons, adults who were consistently inactive throughout adulthood were at higher risks for all-cause, cardiovascular disease-related, and cancer-related mortality than physically active individuals.36 Yet, increasing physical activity later in adulthood (40-61 years) was associated with a lower mortality risk that was similar to those associated with being physically active across the adult lifespan (15-61 years). These results suggest that midlife is not too late to begin engaging in physical activity for health.

40-year-old triathlete

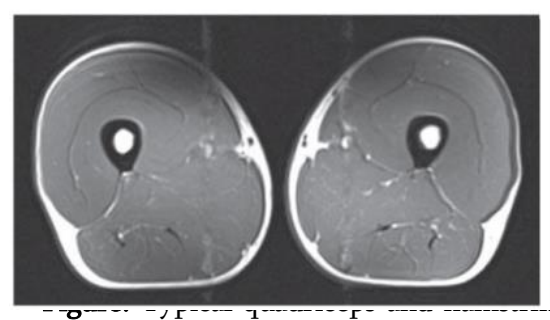

sedentary man (middle panel), and a 70-year-old triathlete (right panel). Reprinted by permission of Taylor \& Francis Ltd (http://www.tandfonline.com) from Wroblewski AP, Amati F, Smiley MA, Goodpaster B, Wright V. Chronic exercise preserves lean muscle mass in masters athletes. The Physician and Sportsmedicine. 2011;39:172-178.

74-year-old triathlete

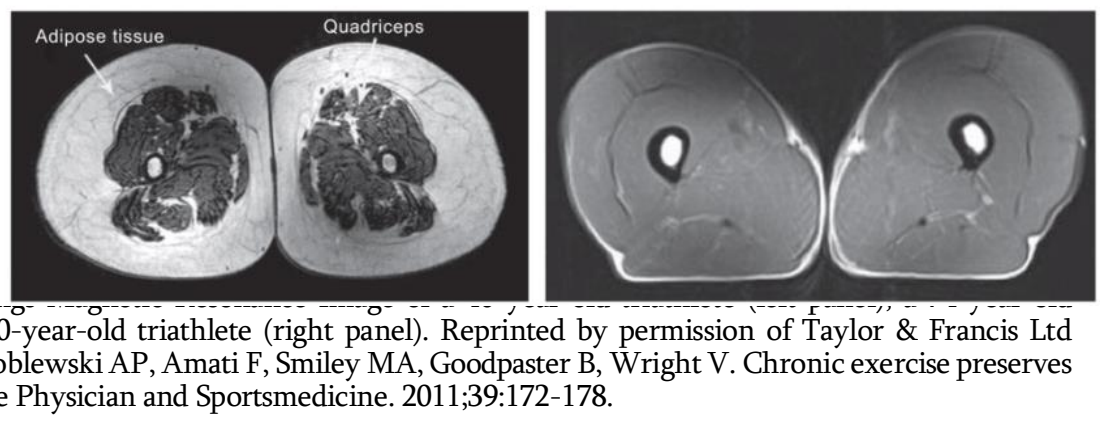




\section{Education and Rehabilitation}

Physical therapists are experts in physical activity, defined as any bodily movement produced by skeletal muscles that requires energy expenditure - including activities undertaken while working, playing, carrying out household chores, travelling, and engaging in recreational pursuits.37 This expertise should be used to help people reach the recommendations of physical activity to optimize their health and extend their life, no matter their age. Physical therapists should serve as primary educators regarding the idea that physical inactivity is a behavioral disorder resulting from multidimensional factors. Being cognizant of these factors, such as our automatic attraction to energetic cost minimization, 17,18 is the first step towards a more active lifestyle. For instance, greater awareness regarding physical inactivity can lead to the development of cognitive or environmental strategies to counteract this automatic attraction. Physical therapists should also inform the public that being physically active22,23 does not necessarily require specific exercise - a subset of physical activity that is planned, structured, and repetitive 37 - or doing sport - which involves competition. Walking in the street is also a physical activity. Individuals performing the least physical activity benefit most by even modest increases in moderate-to-vigorous physical activity.23 Physical therapists should emphasize that clients cannot afford to miss out on this inexpensive path to a healthier life. Recommendations emphasize that moving more and sitting less will benefit nearly everyone.23 Another central point to the rehabilitation of physical inactivity is to monitor the pleasure associated with different intensities of physical activity.38 This pleasure is likely to foster longer engagement in the activity, especially when it is experienced at the end of the activity.39 Additional research is required to build and implement more efficient rehabilitation programs to ensure patients receive comprehensive care aiming to cure a physical inactivity disorder. Physical therapists feel confident, more than physicians, 40 in giving general advice to patients on a physically active lifestyle and suggesting specific physical activity programs.41

\section{Conclusion}

Physical inactivity accurately matches the definition of a behavioral disorder, which emphasizes the necessity to provide care for physically inactive people. As movement specialists and primary care practitioners, physical therapists are key health professionals in preventing, diagnosing, and rehabilitating this disorder. As such, they should define the gold standard for the assessment of the physical inactivity disorder. This gold standard will determine whether a physical inactivity disorder is severe enough to be qualified for reimbursement. Such reimbursement can result in the emergence of certified clinical specialists able to develop a greater depth of knowledge and skills related to physical inactivity.

\section{References}

1-World Health Organization. Constitution. https://www.who.int/about/who-we-are/constitution. Accessed August 2019.

2-Wahid A, Manek N, Nichols M, et al. Quantifying the association between physical activity and cardiovascular disease and diabetes: a systematic review and meta-analysis. J Am Heart Assoc. 2016;5:e002495.

3-Liu X, Zhang D, Liu Y, et al. Dose-response association between physical activity and incident hypertension: a systematic review and meta-analysis of cohort studies. Hypertension. 2017;69:813-820.

4-Aune D, Norat T, Leitzmann M, Tonstad S, Vatten LJ. Physical activity and the risk of type 2 diabetes: a systematic review and dose-response metaanalysis. Eur J Epidemiol. 2015;30:529-542.

5-Moore SC, Lee IM, Weiderpass E, et al. Association of leisure-time physical activity with risk of 26 types of cancer in 1.44 million adults. JAMA Intern Med. 2016;176:816-825.

6-Schuch F, Vancampfort D, Firth J, et al. Physical activity and sedentary behavior in people with major depressive disorder: a systematic review and meta-analysis. J Affect Disord. 2017;210:139-150.

7-Bleich SN, Vercammen KA, Zatz LY, Frelier JM, Ebbeling CB, Peeters A. Interventions to prevent global childhood overweight and obesity: a systematic review. Lancet Diabetes Endocrinol. 2018;6:332-346.

8-Lee IM, Shiroma EJ, Lobelo F, et al. Effect of physical inactivity on major non-communicable diseases worldwide: an analysis of burden of disease and life expectancy. Lancet. 2012;380:219-229.

9-World Health Organization. ICD-11 for mortality and morbidity statistics. https://icd.who.int/browse11/1-m/en. Accessed August 2019.

10-Guthold R, Stevens GA, Riley LM, Bull FC. Worldwide trends in insufficient physical activity from 2001 to 2016: a pooled analysis of 358 population-based surveys with 1.9 million participants. Lancet Glob Health. 2018;6:e1077-e1086.

11-Althoff T, Sosič R, Hicks JL, King AC, Delp SL, Leskovec J. Large-scale physical activity data reveal worldwide activity inequality. Nature. 2017;547:336-339.

12-Kohl HW 3rd, Craig CL, Lambert EV, et al. The pandemic of physical inactivity: global action for public health. Lancet. 2012;380:294-305.

13-Chodzko-Zajko WJ. The World Health Organization issues guidelines for promoting physical activity among older persons. J Aging Phys Act. 1997;5:1-8.

14-Canadian Fitness and Lifestyle Research Institute. Physical activity monitor: facts and figures. http://www.cflri.ca/sites/default/files/node/95/files/PAM2008FactsFigure s_Bulletin14_Intention_to_be_activeEN.pdf. Accessed August 2019.

15-Rhodes RE, Plotnikoff RC, Courneya KS. Predicting the physical activity intention-behavior profiles of adopters and maintainers using three social cognition models. Ann Behav Med. 2008;36:244-252.

16-Forestier C, Sarrazin P, Allenet B, Gauchet A, Heuzé JP, Chalabaev A. "Are you in full possession of your capacity?". A mechanistic self-control approach at trait and state levels to predict different health behaviors. Pers Individ Differ. 2018;134:214-221.

17-Cheval B, Tipura E, Burra N, et al. Avoiding sedentary behaviors requires more cortical resources than avoiding physical activity: an EEG study. Neuropsychologia. 2018;119:68-80.

18-Cheval B, Radel R, Neva JL, et al. Behavioral and neural evidence of the rewarding value of exercise behaviors: a systematic review. Sports Med. 2018;48:1389-1404.

19-Chatzisarantis NL, Hagger MS, Biddle SJ, Smith B, Wang JC. A metaanalysis of perceived locus of causality in exercise, sport, and physical education contexts. J Sport Exerc Psychol. 2003;25:284-306. 
20-Hagger MS, Chatzisarantis NL. Integrating the theory of planned behaviour and self-determination theory in health behaviour: a metaanalysis. Br J Health Psychol. 2009;14:275-302.

21-Wiers CE, Stelzel C, Gladwin TE, Park SQ, Pawelczack S, Gawron CK, et al. Effects of cognitive bias modification training on neural alcohol cue reactivity in alcohol dependence. Am J Psychiatry. 2015;172:335-43.

22-World Health Organization. Global recommendations on physical activity for health. https://apps.who.int/iris/bitstream/handle/10665/44399/9789241599979_ eng.pdf?sequence=1. Accessed August 2019.

23-Piercy KL, Troiano RP, Ballard RM, Carlson SA, Fulton JE, Galuska DA, George SM, Olson RD. The physical activity guidelines for americans. JAMA. 2018;320:2020-2028.

24-Sylvia LG, Bernstein EE, Hubbard J, Keating L, Anderson EJ. Practical guide to measuring physical activity. J Acad Nutr Diet. 2014 ;114:199-208.

25-den Hoed M, Brage S, Zhao JH, et al. Heritability of objectively assessed daily physical activity and sedentary behavior. Am J Clin Nutr. 2013;98:1317-1325.

26-King AC, Castro C, Wilcox S, Eyler AA, Sallis JF, Brownson RC. Personal and environmental factors associated with physical inactivity among different racial-ethnic groups of U.S. middle-aged and older-aged women. Health Psychol. 2000 Jul; 19:354-64.

27-Cheval B, Orsholits D, Sieber S, Courvoisier D, Cullati S, Boisgontier MP. Age-related decline of cognitive resources precedes and explains the decline in physical activity. SportRxiv. 2019. https://doi.org/10.31236/osf.io/pagx6

28-Cheval B, Rebar AL, Miller MW, et al. Cognitive resources moderate the adverse impact of poor perceived neighborhood conditions on selfreported physical activity of older adults. Prev Med. 2019;126:105741.

29-Cheval B, Sieber S, Guessous I, Orsholits D, Courvoisier DS, Kliegel M, et al. Effect of early- and adult-life socioeconomic circumstances on physical inactivity. Med Sci Sports Exerc. 2018;50:476-485.

30-Phillips SM, Parise G, Roy BD, Tipton KD, Wolfe RR, Tamopolsky MA. Resistance-training-induced adaptations in skeletal muscle protein turnover in the fed state. Can J Physiol Pharmacol. 2002;80:1045-1053.

31-Foong YC, Chherawala N, Aitken D, Scott D, Winzenberg T, Jones G. Accelerometer-determined physical activity, muscle mass, and leg strength in community-dwelling older adults. J Cachexia Sarcopenia Muscle. 2016;7:275-283.

32-Janssen I, Shepard DS, Katzmarzyk PT, Roubenoff R. The healthcare costs of sarcopenia in the United States. J Am Geriatr Soc. 2004;52:80-85.

33-Johansson J, Nordström A, Nordström P. Objectively measured physical activity is associated with parameters of bone in 70-year-old men and women. Bone. 2015;81:72-79.

34-Castrogiovanni P, Trovato FM, Szychlinska MA, Nsir H, Imbesi R, Musumeci G. The importance of physical activity in osteoporosis. From the molecular pathways to the clinical evidence. Histol Histopathol. 2016;31:1183-1194.

35-Staiano AE, Martin CK, Champagne CM1, Rood JC, Katzmarzyk PT. Sedentary time, physical activity, and adiposity in a longitudinal cohort of nonobese young adults. Am J Clin Nutr. 2018;108:946-952.

36-Saint-Maurice PF, Coughlan D, Kelly SP, et al. Association of leisure-time physical activity across the adult life course with all-cause and causespecific mortality. JAMA Netw Open. 2019;2:e190355.

37-Caspersen CJ, Powell KE, Christenson GM. Physical activity, exercise, and physical fitness: definitions and distinctions for health-related research. Public Health Rep. 1985;100:126-131.

38-Ekkekakis P, Parfitt G, Petruzzello SJ. The pleasure and displeasure people feel when they exercise at different intensities: decennial update and progress towards a tripartite rationale for exercise intensity prescription. Sports Med. 2011;41:641-671.

39-Kahneman D, Fredrickson BL, Schreiber CA, Redelmeier DA. When more pain is preferred to less: adding a better end. Psychol Sci. 1993;4:401405.

40-Buffart LM, van der Ploeg HP, Smith BJ, Kurko J, King L, Bauman AE. General practitioners' perceptions and practices of physical activity counselling: changes over the past 10 years. Br J Sports Med. 2009;43:1149-53.

41-Shirley D, van der Ploeg HP, Bauman AE. Physical activity promotion in the physical therapy setting: perspectives from practitioners and students. Phys Ther. 2010;90:1311-22. 